Revista Digital Universitaria

Vol. 22, Núm. 6, noviembre-diciembre 2021

\title{
Lo que aprendimos a un año de haber comenzado la pandemia
}

\author{
Alan Sánchez Vázquez
}

\section{Resumen}

Resulta importante hacer una reflexión en retrospectiva acerca del momento histórico en que nos encontramos como estudiantes, profesores y seres humanos. Es evidente que las dimensiones educativa y social se han visto trastocadas a un año de haber iniciado el confinamiento estricto en México y en el mundo. Muchas cosas se modificaron, pero ¿cómo lo estamos sobrellevando?

En este breve artículo, se hace un repaso sobre lo que hemos cambiado y mejorado, y que, una vez que regresemos a la llamada "nueva normalidad", integraremos en nuestra nueva vivencia, desde lo académico hasta los aspectos social y emotivo.

Palabras clave: pandemia, aprendizaje, habilidades, sociedad.

\section{WHAT WE LEARNED A YEAR AFTER THE BEGINNING OF THE PANDEMIC}

\begin{abstract}
It is important to reflect in retrospect on the historical moment in which we find ourselves as students, teachers, and human beings. Evidently, the educational and social dimensions have been disrupted one year after the beginning of the strict confinement in Mexico and in the world. Many things have been modified, but how are we coping with it?

In this short article, we review what we have changed and improved, and that, once we return to the so-called "new normal", we will integrate into our new experience, in the academic, social and emotional aspects.
\end{abstract}

Keywords: pandemic, learning, skills, society 
Profesor de Carrera Titular A de Tiempo Completo en la ENES León desde 2013. Ha trabajado en la Universidad Nacional Autónoma de México (UNAM) desde 2002. Cursó la Licenciatura en Enseñanza de Inglés en la Facultad de Estudios Superiores Acatlán y la Maestría en Lingüística Aplicada, en la cual desarrolló un estudio bajo la línea de investigación en aprendizaje autónomo y ambientes digitales, que lleva por título "Aprendizaje de la Entonación por alumnos de ccr en ambiente de autonomía: un estudio de caso". Ha participado como ponente en distintos coloquios y conferencias internacionales entre los que destacan el Pronunciation in Second Language Learning and Teaching en Northern Arizona University en 2019, el Encuentro de Lenguas en Contacto Español, Inglés y Lenguas mexicanas en 2015 por la Universidad Autónoma de Nayarit, así como English Pronunciation: Issues and Practices, que tuvo lugar en Mayo de 2013 en la ciudad de Murcia, España. Ha participado en distintos grupos de trabajo entre los que destacan el proyecto English Media en línea y más recientemente en la plataforma Ambiente Virtual de Idiomas, también de la unam.

Para Elenita

\section{Introducción}

Figura 1. Ciudad Universitaria UNAM (Ted's photos - For Me \& You, CC BY-NC-SA 2.0)

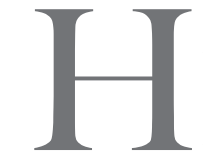

ace aproximadamente un año y algunos meses comenzó el período de confinamiento estricto en México, y nuestras labores educativas y académicas cambiaron. El trayecto hacia la universidad, la gente que

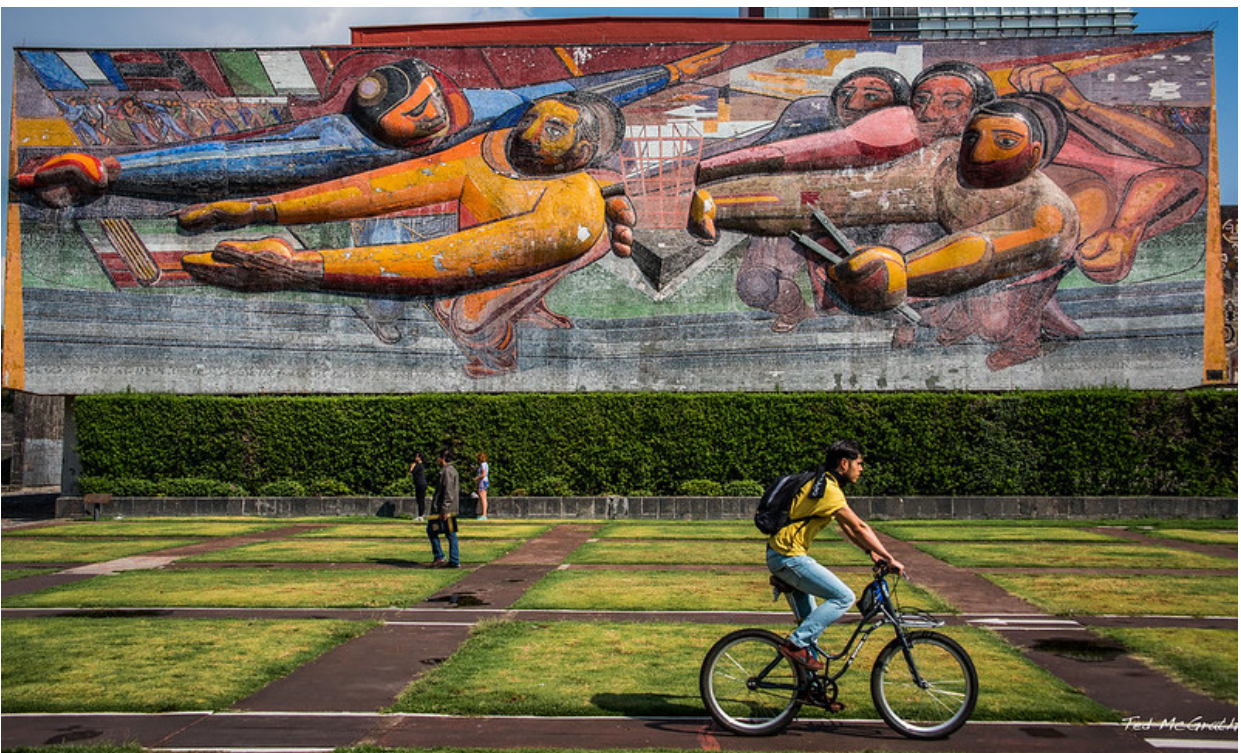
solíamos ver a nuestro paso, los holas, los buenos días, los desayunos en cafeterías, y las miradas de saludo que intercambiábamos en el transcurso de los pasillos de nuestra casa de estudios, desde hace tiempo ya no están. A más de un año de ese momento, ¿en dónde estamos como académicos, como estudiantes? ¿Qué hemos aprendido?

El período de contingencia por el virus SARS-CoV-2 (covid-19) puede ser visto desde distintas perspectivas. En este breve artículo abordaré dos dimensiones, la dimensión educativa y la dimensión social. 


\section{Dimensión educativa}

En el área de idiomas, en la que me desempeño, podemos decir que desde hace ya bastante tiempo hemos trabajado en plataformas educativas en línea, que han buscado desarrollar y fomentar el aprendizaje autónomo, donde el alumno se forme en estrategias que le permitan llevar a cabo un proceso de aprendizaje autorregulado, y que existan materiales y recursos educativos que ayuden al logro de las metas de aprendizaje en ambiente de autonomía. Prueba de ello son los portales English Media y Ambiente Virtual de Idiomas, proyectos de la unAm en donde he tenido la oportunidad y honor de participar, y que durante la contingencia han sido ampliamente difundidos y utilizados por muchos estudiantes de la Universidad Nacional (ver figuras 2 y 3 ).

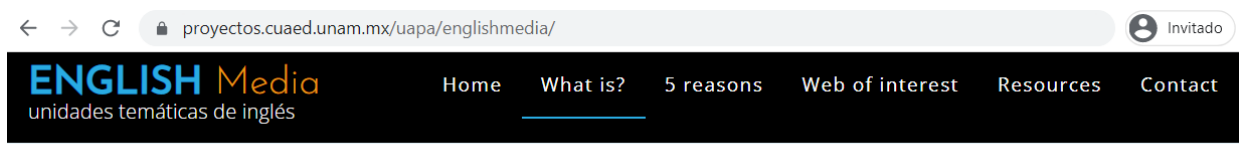

Figura 2. Portal de Proyectos English Media (CUAED, s.f.).

Figura 3. Portal de Ambiente Virtual de Idiomas (CUAIEED, s.f.).

\section{What is ENGLISH Media?}

Una de las líneas de trabajo del Plan General de Desarrollo 2007-2011 de la Rectoría de la UNAM consiste en vincular la enseñanza del inglés en el bachillerato con la licenciatura y el posgrado, con la finalidad de fortalecer el aprendizaje de este idioma y, de esta manera, darle a los egresados una herramienta de trabajo, estudio y cultura. Por ello, la comunidad universitaria consideró que era cada vez más necesario ampliar el aprendizaje de inglés, de una sola habilidad (comprensión de lectura) a las cuatro habilidades (comprensión de lectura, producción oral, comprensión auditiva y producción escrita).

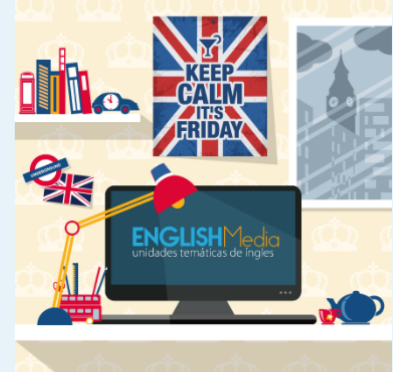

\section{Ver más}

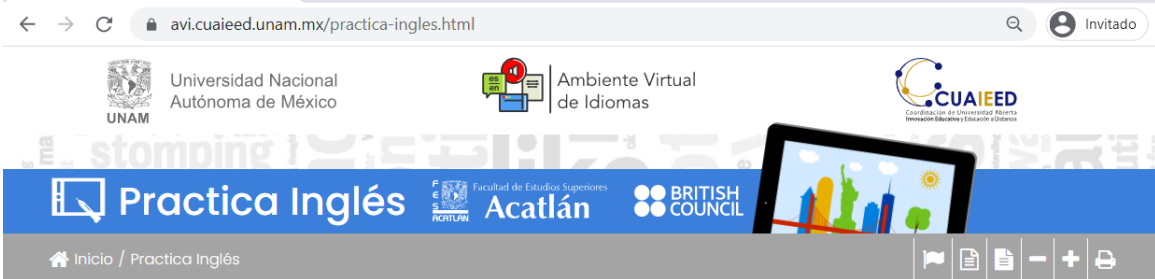

令

四

Inicio Practica

Evalúate Aprende Certíícate

Desarrolla tus habilidades de Inglés a través de las 194 Unidades Temáticas que se encuentran disponibles para tu aprendizaje del idioma inglés.

Uిी

Unidad de Apoyo para el Aprendizaje
La UAPA es una unidad de aprendizaje que tiene la caracteristica de ser

autogestiva y contiene partes de aprendizaje con rúbricas y

retroalimentación que te permitirán autoevaluarte. Cada UAPA tiene una sección de Contenido que presenta información gramatical, audios que te ayudarán a desarrollar tu comprensión auditiva, textos para practicas tus estrategias de comprensión lectora, actividades de producción oral y finalmente, una sección de producción escrita, donde crearás escritos bajo ciertos parámetros. 
Para distintos autores dentro del área del aprendizaje de idiomas, pero incluso en ámbitos como la filosofía o psicología, la autonomía no es un estado finito, sino un continuo en distintos niveles o estadios susceptibles a desarrollarse (Little, 2017, p. 25; Hiago y Sade, 2020, p. 29). Así, nuestros alumnos e incluso nosotros como académicos transitamos en alguna parte de este continuo. De ahí la importancia del desarrollo de materiales, recursos y actividades, que fomenten en los alumnos estrategias de autorregulación, que los ayuden a avanzar en el proceso de volverse más y mejores aprendientes autónomos.

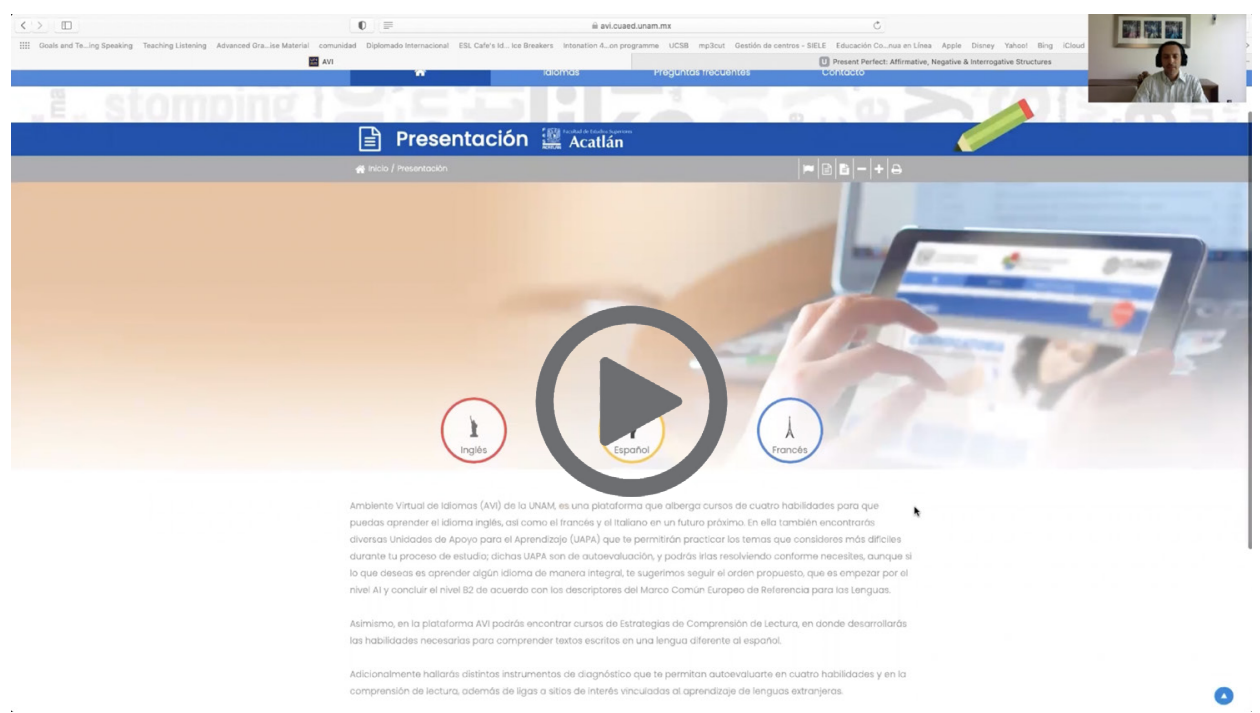

Video . Plataforma Universitaria Ambiente Virtual de Idiomas.

A lo anterior se le añade el incipiente conocimiento que muchos teníamos sobre plataformas de comunicación virtual —como Zoom, Meet, Webex-, o las de gestión de contenidos —como Google Classroom o Schoology-. Aprender a utilizar dichas herramientas y recursos añadidos fue algo que aprendimos prácticamente en la marcha, y también gracias a los innumerables cursos que se ofrecieron y se siguen ofertando en la Universidad. Aparentar que nuestros alumnos o nosotros mismos fuimos expertos desde el inicio y que no hubo equivocaciones —como abrir dos sesiones de Zoom y luego no saber a cuál debíamos ingresar $\because$ - sería tanto como pretender que la primera clase que dimos como docentes (en presencial) fue un éxito rotundo. Indudablemente, hubo mucho aprendizaje en cuanto a habilidades académicas que tanto docentes como discentes adquirimos a lo largo de este año de contingencia.

Lo anterior sólo significa que se ha avanzado un poco en este ámbito, definitivamente hay aspectos que deben abordarse, y siempre hay áreas de oportunidad. No obstante, reconocer aquello que hemos logrado nos permite observar también lo que aún falta por alcanzar.

\section{Dimensión social}

A lo largo de este último año hemos atravesado por distintas situaciones, algunas buenas y otras nada placenteras. En un inicio, algunos de nosotros 
llegamos a "disfrutar" del quedarnos en casa y no salir. De inmediato surgieron algunas ventajas mundanas como no gastar tanto combustible, la idea de pasar más tiempo con nuestras familias y mascotas, la posibilidad de comer más sano, actividades que, desde el privilegio de tener un trabajo que nos permite desempeñar nuestra labor académica desde casa, parecen positivas.

Sin embargo, no es la realidad de todos. Definitivamente no fue la realidad de muchos de nuestros estudiantes, compañeros, vecinos, o familiares. Algunos de los padres de nuestros alumnos o nuestros propios estudiantes sufrieron casi de inmediato un recorte en su sueldo y tuvieron que buscar otros medios para obtener recursos económicos a pesar de la contingencia. Algunos perdieron su trabajo.

Durante los primeros meses de la emergencia sanitaria, no sólo se hizo evidente la necesidad de mejorar la infraestructura de la red de internet en el país. De hecho, en términos más reales, muchos de nuestros alumnos y algunos profesores simplemente no tenían acceso a ella. Algunos tuvieron que ir a cafésinternet a tomar clase, compartir sus equipos de cómputo con otros miembros de su familia, o algunas otras opciones, las cuales probablemente no implicaban las mejores situaciones para atender una clase virtual.

Independientemente de los esfuerzos realizados por cada uno de los académicos, los llamados desde las instituciones educativas a la flexibilidad, a promover la empatía, a tratar de entender la realidad del otro, fueron muy necesarios y relevantes. Fue a través de la comprensión de la realidad de nuestros estudiantes, que adecuamos actividades, tiempos y formatos de entrega. En definitiva, no es igual una clase presencial a una clase virtual, y a todos nosotros la realidad de nuestros alumnos, sus necesidades, limitaciones, expectativas y la propia problemática social y personal se nos vino encima. Empatizar con nuestros semejantes y auxiliar cuando era posible fueron las constantes.

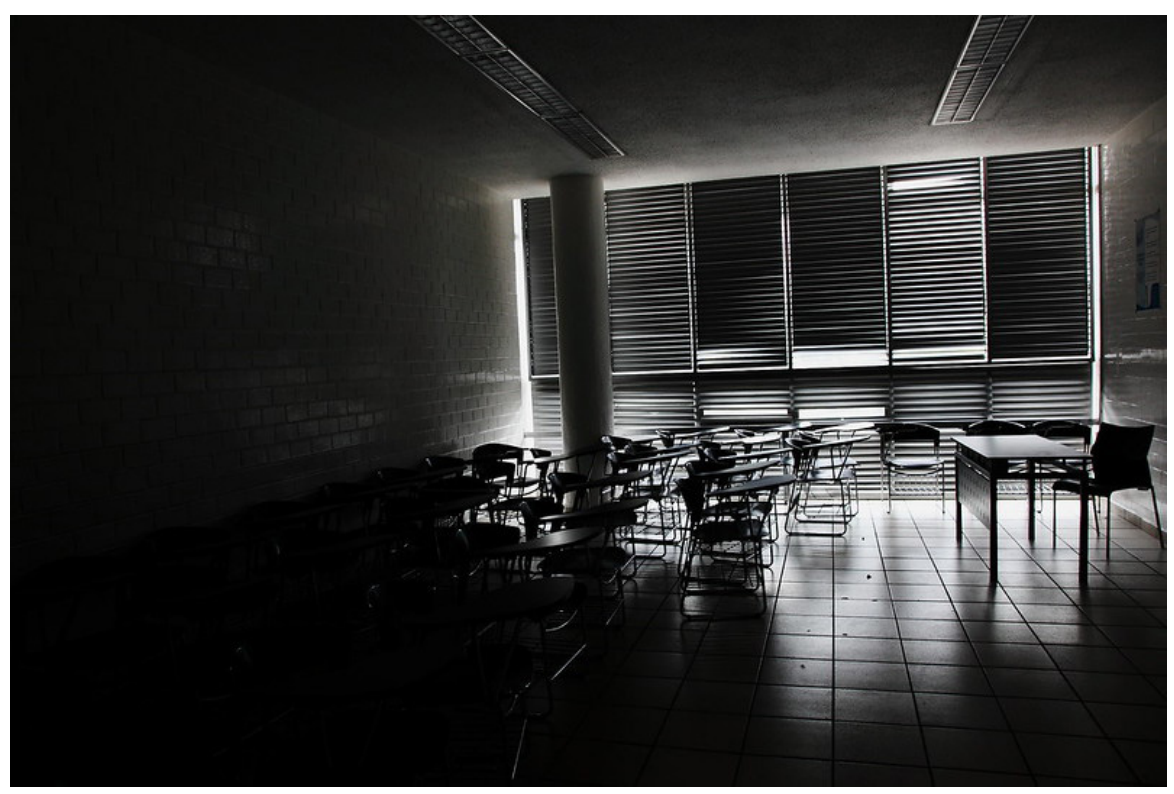


Figura 5. "Vaciando el supermercado" (Eneas De Troya, CC BY 2.0).

Figura 6. Nube de palabras por alumnos de la enes Unidad León.
Luego, vinieron cosas más complicadas. La pérdida de un ser querido puede trastornar la vida de cualquiera. Bajo una situación de pandemia, con restricciones para reunirse, se volvió complicado acompañar físicamente a nuestras propias familias. No obstante, la cercanía afectiva que se brindó mediante los distintos medios tecnológicos sirvió de apoyo para quienes estuvimos en esa situación. Entonces, el llamado a ser flexibles y a ser empáticos con nuestros estudiantes y con nuestra comunidad en general no sólo vino de la Universidad, sino de la propia vida, que nos empujó a intentar comprender la otredad, a apoyarnos, y a acompañarnos en una situación que, como hemos dicho, fue cambiando a lo largo de los meses.

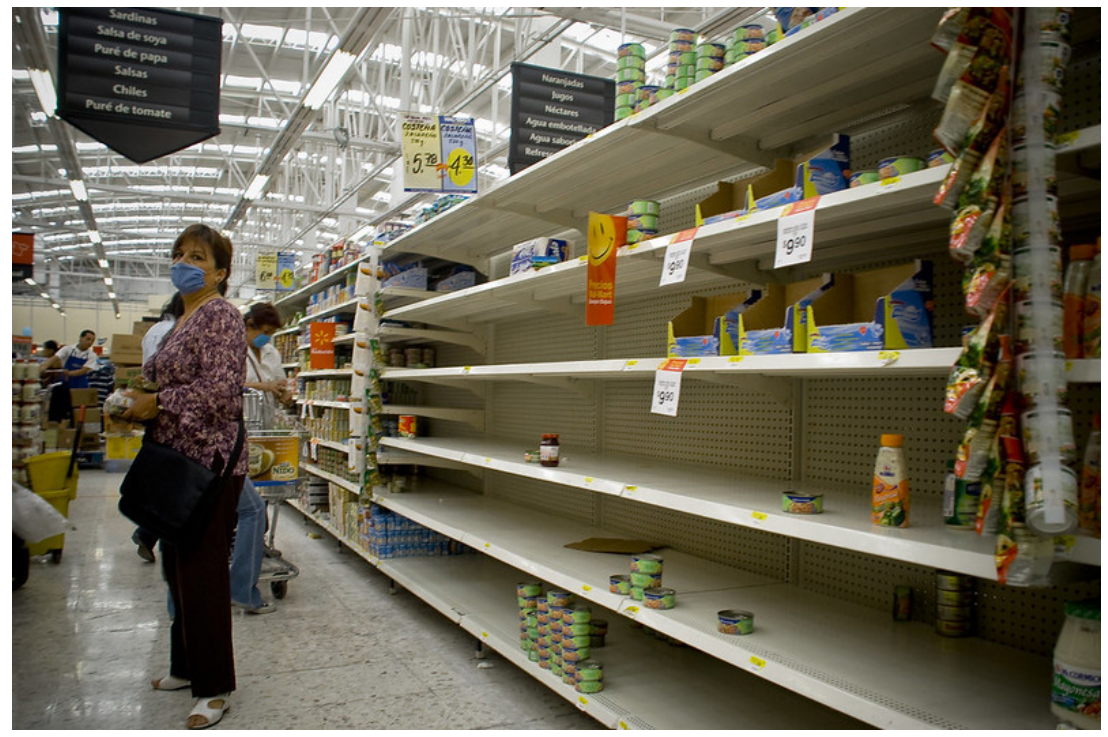

En un ejercicio con 60 alumnos de la ENEs Unidad León, se les preguntó qué habían aprendido después de estar en confinamiento durante un año y en las condiciones actuales. Para muchos de ellos la experiencia ha tenido una suerte de sabor agridulce, por la fortuna de estar en casa, pero con el miedo e incertidumbre de no querer que su familia se contagie, esto aunado al estrés que significa trabajar y pasar mucho tiempo frente a la computadora. Para la gran mayoría, lo más importante fue valorar la salud y, por supuesto, la familia. Mediante una herramienta de nubes de palabras hemos incluido las ideas más frecuentes en las experiencias compartidas por los alumnos (ver figura 6).

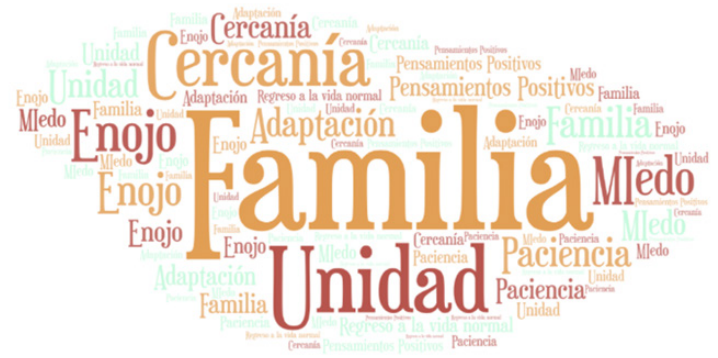




\section{Y, entonces, ¿qué hemos aprendido?}

Hemos aprendido muchas y muy innovadoras estrategias docentes para apoyar y ayudar a construir el aprendizaje de nuestros alumnos a distancia. Aun cuando no era la formación de los docentes, nos hemos convertido en profesores en línea. Hemos aprendido a utilizary a sacar el mayor provecho de las herramientas digitales y recursos electrónicos que nos ofrece nuestra casa de estudios, quizá con un poco de miedo e inseguridad en algunos casos, pero siempre con la convicción de promover el aprendizaje autónomo como parte de la esencia de la Universidad Nacional.

A pesar de que para muchos de nuestros alumnos el proceso de aprendizaje en este año ha sido sumamente complicado y confuso en muchas ocasiones, ellos, sin duda, han aprendido mucho acerca de autonomía y han aplicado (aún sin darse cuenta) estrategias que les permiten autorregular su aprendizaje y mantenerse motivados. Sí, aún queda mucho por aprender, pero una vez que regresemos a las aulas no seremos los mismos, volveremos con habilidades académicas que antes no teníamos y seremos capaces de aplicarlas en nuestra vida diaria.

Por otra parte, también hemos aprendido que reconocer, validar y empatizar con las situaciones que nuestra comunidad (alumnos, profesores, administrativos) ha vivido en este período nos permite conectar mejor y entender que más allá del ámbito educativo, existe una dimensión social y afectiva que forma parte integral de nosotros y que puede ayudar o inhibir que nuestros alumnos desarrollen sus habilidades y conocimientos. Ser flexible y empático con el otro será una habilidad que pondremos en práctica de ahora en adelante, tanto en la realidad a distancia como en la presencial. En palabras de Thedore Roosevelt: "A nadie le importa cuánto sabes, hasta que saben cuánto te importa".

\section{Referencias}

* cuaed. (s.f). English Media. Unidades temáticas de inglés. https://cutt.ly/cRFaVHE

* cuaieed. (s.f.). Ambiente Virtual de Idiomas. https://avi.cuaed.unam.mx

* Hiago, C. y Sade, T. (2020, 27 de enero). The learning autonomy of the visually impaired students in language education and language acquisition. https://doi. org/10.31226/osf.io/nbg5r

* Little, D., Dam, L. y Legenhausen, L. (2017). Language Learner Autonomy: Theory, Practice and Research. Multilingual Matters.

* Rueda Beltrán, M. (2010). Autoevaluación y autonomía. Perfiles Educativos, 32(130). https://doi.org/10.22201/iisue.24486167e.2010.130.20568

* Theodore Roosevelt Quotes (Author of The Rough Riders). (s. f.). Goodreads. https://www.goodreads.com/author/quotes/44567.Theodore_Roosevelt

* unam global. (s.f.). Pandemia covid-19. https://cutt.ly/fRFp3HY 


\section{Cómo CITAR ESTE ARTículo}

* Sánchez Vázquez, Alan. (2021, noviembre-diciembre). Lo que aprendimos a un año de haber comenzado la pandemia. Revista Digital Universitaria (RDU), 22(6). http://doi.org/10.22201/cuaieed.16076079e.2021.22.6.7 